This document is published in:

International Journal of Impact Engineering, 2013, 54, 206-

216. Doi: http://dx.doi.org/10.1016/j.ijimpeng.2012.11.003.

(c) Elsevier 


\title{
Finite element analysis of AISI 304 steel sheets subjected to dynamic tension: The effects of martensitic transformation and plastic strain development on flow localization
}

\author{
J.A. Rodríguez-Martínez ${ }^{\mathrm{a}, *}$, D. Rittel ${ }^{\mathrm{a}, \mathrm{b}}$, R. Zaera ${ }^{\mathrm{a}}$, S. Osovski ${ }^{\mathrm{b}}$ \\ a Department of Continuum Mechanics and Structural Analysis, University Carlos III of Madrid, Avda. de la Universidad, 30,28911 Leganés, Madrid, Spain \\ ${ }^{\mathrm{b}}$ Faculty of Mechanical Engineering, Technion, 32000 Haifa, Israel
}

Keywords:

Dynamic tension

Necking

Strain induced martensitic transformation

Critical impact velocity

\begin{abstract}
A B S T R A C T
The paper presents a finite element study of the dynamic necking formation and energy absorption in AISI 304 steel sheets. The analysis emphasizes the effects of strain induced martensitic transformation (SIMT) and plastic strain development on flow localization and sample ductility. The material behavior is described by a constitutive model proposed by the authors which includes the SIMT at high strain rates. The process of martensitic transformation is alternatively switched on and off in the simulations in order to highlight its effect on the necking inception. Two different initial conditions have been applied: specimen at rest which is representative of a regular dynamic tensile test, and specimen with a prescribed initial velocity field in the gauge which minimizes longitudinal plastic wave propagation in the tensile specimen. Plastic waves are found to be responsible for a shift in the neck location, may also mask the actual constitutive performance of the material, hiding the expected increase in ductility and energy absorption linked to the improved strain hardening effect of martensitic transformation. On the contrary, initializing the velocity field leads to a symmetric necking pattern of the kind described in theoretical works, which reveals the actual material behavior. Finally the analysis shows that in absence of plastic waves, and under high loading rates, the SIMT may not further increase the material ductility.

(c) 2012 Elsevier Ltd. All rights reserved.
\end{abstract}

\section{Introduction}

The characterization of the mechanical properties of materials at high strain rates has become increasingly relevant for the industry. Accurate knowledge of those properties is usually required in different engineering applications such as aeronautical $[1,2]$, automotive $[3,4]$, naval $[5,6]$ and manufacturing $[7,8]$, where service conditions involve large strains at high strain rates.

Among the experimental characterization tests, the uniaxial tensile arrangement is definitely the most commonly used due to its simplicity. The uniform state of stress and strain along the gauge for this test greatly simplifies the interpretation of results. However the homogeneous deformation eventually ceases due to the onset of necking in the specimen. Necking in uniaxial stress conditions has been largely studied since it indicates the onset of a process which leads to material failure, and therefore determines the suitability of materials to absorb energy. For quasi-static loading,

\footnotetext{
Corresponding author. Tel.: +34 916248460; fax: +34 916249430

E-mail address: jarmarti@ing.uc3m.es (J.A. Rodríguez-Martínez).
}

Considère [9] showed that in a long and thin bar, the neck develops at maximum load. Within the framework developed by Hill [10] on the theory of bifurcation in elastic-plastic solids, different authors $[11,12]$ demonstrated that the strain at maximum load provides a lower bound to the strain at which bifurcation occurs; in specimens showing large length/width ratio localization starts slightly after the maximum load whereas in specimens showing small length/width ratio localization is further delayed.

Under dynamic conditions, the onset of necking is additionally influenced by other factors. Different authors concluded that the condition for instability in tensile tests also depends on the strain rate sensitivity of the material; Woodford [13] and Ghosh [14] collected data from tensile tests of a number of metals, showing a strong delay in necking with increasing logarithmic strain rate sensitivity. In the meanwhile, a number of theoretical works were developed to explain this influence. Hart [15] formulated a stability criterion for materials exhibiting strain rate sensitivity that was later re-examined by Ghosh [16]. Klepaczko [17] developed a theoretical framework to include the effect of temperature in the analysis of instabilities in rate-dependent materials. Hutchinson and Neale [18] concluded that strain rate sensitivity has a strong 
influence on the post-uniform elongation, retarding necking localization. In the recent years, a number of papers has been published which provided further understanding of the interplay between strain rate sensitivity and necking formation [19-23]. Inertia was the following effect considered as influential in the development of dynamic instabilities. Fressengeas and Molinari [24] used a perturbation analysis to discuss dynamic effects on ductility, showing that geometrical perturbations are stabilized by inertia effects. Using a bifurcation analysis, in this case under plain strain conditions, Shenoy and Freund [25] demonstrated also the stabilizing effect of inertia. More recently, one should mention a number of theoretical and numerical works that have provided additional verification of the benefits provided by material inertia to delay necking formation [19,20,26-29]. Material strain hardening is certainly an additional factor which enhances ductility. The Considère condition [9] clearly outlines the favorable effect of a high strain-hardening coefficient in quasi-static conditions, but this effect has also been addressed by different authors under high rate loading conditions [16,17,21,29,30]. These studies considered the influence of parameters, such as material inertia, strain hardening and strain rate sensitivity in absence of wave propagation phenomena.

Among the previous effects modifying the onset of dynamic necking, strain hardening is known to be influenced by microstructural effects such as dynamic phase transformations. Specifically, Strain Induced Martensitic Transformation (SIMT) acts as a highly potent mechanism of martensite germination associated with plastic deformation in the austenitic phase. The transformation of austenite into martensite is comparable to a dynamic composite effect due to the progressive appearance of the martensite during straining, enhancing strain hardening of the steel. Different authors have recently addressed the role played by the SIMT in the dynamic behavior of different steel grades [31-34]. It was observed that this phase transformation mechanism can reasonably be expected to affect the propensity of a material for dynamic necking, a point that deserves further investigation.

High-speed hydraulic machines and Split Hopkinson (Kolsky) Bar devices have been successfully applied to investigate the mechanical behavior of materials at intermediate to high strain rates $[35,36]$, the goal being the determination of the intrinsic properties of the tested material under uniform uniaxial stress conditions. Therefore different authors introduced original tensile specimens to optimize the geometry, favor a homogeneous strain field and delay instabilities [37-40]. However, imposing a velocity boundary condition on one side of a solid at rest - which is needed for dynamic testing - necessarily produces a plastic wave front. In such a case the strain gradients due to the effect of plastic wave propagation in the specimen may hinder the actual constitutive behavior of the material. Under large impact velocities, the strain field becomes rapidly non-uniform, affecting the ductility of the specimen and shifting the position of the neck in the sample. Hopkinson [41,42] and Hopkinson [43] analyzed the dynamic loading of steel wires and observed that they broke at different points along their length depending on the loading velocity; the elastic wave propagation phenomena were considered as responsible for this behavior. Furthermore, Von Kàrman and Duwez [44] and Clark and Wood [45] reported a Critical Impact Velocity (CIV) such that, when exceeded, the force equilibrium is not fulfilled and necking occurs close to the impacted end with negligible subsequent plastic strain in the rest of the specimen. The first theoretical work on CIV was proposed by Von Kàrman and Duwez [44], while Klepaczko $[17,46]$ extended this theory to consider strain rate and temperature effects.

In order to avoid the drawback of the wave disturbances on determining material ductility at high strain rates, the ring expansion test was developed [47] and investigated by different authors $[19,30,48,49]$. Here, complications resulting from wave propagation are eliminated until the onset of necking due to the symmetry of the problem, which implies that the influence of loading velocity on material ductility can be studied, virtually, without limits on the applied velocity. However, the complicated experimental arrangement required for the ring expansion test impedes the determination of the material stress-strain characteristics. Thus, the uniaxial tensile test, in its dynamic version, cannot simply be ruled out because of suspected wave-related effects, at the benefit of the ring expansion test. This remark calls for an in-depth additional evaluation of the dynamic tensile test, in order to better assess its benefits and also its limitations, while taking into account the occurrence of dynamic phase transformation of the above-mentioned kind.

This paper investigates necking formation in AISI 304 steel sheets subjected to dynamic tension. This steel grade is considered a reference metastable austenitic stainless steel for studying the SIMT process at high strain rates since it shows a large amount of transformed martensite even under adiabatic conditions [50]. The analysis emphasizes the effects of martensitic transformation and plastic wave propagation on flow localization and sample ductility. For that purpose, finite element simulations of a dynamic tensile test have been performed, in which the SIMT has been switched on and off to disclose the effect of the enhanced strain hardening produced by the SIMT. In addition, two different initial conditions have been considered: specimen at rest and specimen with an initial velocity field in the gauge. The analysis shows that in absence of an initial velocity field and within certain ranges of impact velocity the neck may be shifted from the middle toward the ends of the specimen. The shifting of the neck is found to be a limiting factor for the sample ductility. On the contrary, the initial velocity field minimizes the propagation of plastic waves along the longitudinal direction of the sample, thus leading to a rather symmetric necking pattern of the kind described in aforementioned theoretical works $[19,27]$. Plastic wave propagation phenomena not only affects the ductility of the specimen but may also invert the expected increase in energy absorption due to the SIMT. Furthermore, the role played by the plastic wave propagation hiding the actual material behavior has been highlighted; and a range of strain rates for which the measured dynamic tensile characteristics of a material can be considered as actual material properties has been determined. Finally the analysis shows that in absence of plastic waves, and under high loading rates, the SIMT may not provide further benefits to the material ductility.

The paper is organized as follows. Section 2 provides a brief summary of the thermo-viscoplastic constitutive equations used to model the mechanical behavior of the AISI 304 steel and emphasizes the enhanced strain hardening of the material due to martensitic transformation. Section 3 describes the different finite element models developed to perform the study. In Section 4 the results of the numerical simulations are shown and discussed, focusing the attention on the effects of martensitic transformation and plastic wave propagation on flow localization and sample ductility. The concluding section outlines the main outcomes of this study.

\section{Constitutive modeling of strain induced martensitic transformation and calculation of effective properties}

A complete description of the model, the values of the parameters identified for AISI 304 stainless steel and its validation with dynamic tensile tests results can be found in Zaera et al. [34,51], but here the key points of the constitutive formulation are further discussed for completeness. The constitutive description is based 
on the previous works of Olson and Cohen [52], Stringfellow et al. [53] and Papatriantafillou et al. [54], all developed to account for SIMT in steels containing metastable austenite, and includes modifications in the following items:

- According to Olson and Cohen [52] the intersection of shear bands in austenite is considered as the dominant mechanism of SIMT. The kinetics of the transformation is described by an exponential expression in which the plastic deformation in austenite is multiplied by a coefficient $\alpha$ favoring the shear band deformation mode. The parameter $\alpha$ decreases with temperature, as observed by Olson and Cohen [52]. The following phenomenological law is proposed to fit this dependence

$$
\alpha(\Theta)=\alpha_{0}\left[1-\Theta \exp \left(\alpha_{1}\left(1-\Theta^{-1}\right)\right)\right]
$$

where $\alpha_{0}$ and $\alpha_{1}$ are constants and $\Theta$ is a normalized temperature. In comparison with the polynomial expressions applied by other authors to describe the change of $\alpha$ with temperature $[52,55,56]$, the one proposed in this work facilitates to capture the decrease of the transformation rate with increasing temperature within the temperature range in which the SIMT occurs.

- The linearly temperature dependent normalized thermodynamic driving force for the martensitic transformation, proposed by Stringfellow et al. [53], is replaced here by an exponential equation. This new law provides a greater temperature sensitivity of the rate of martensitic transformation. This becomes relevant at high strain rates where the temperature rise of the material results from the adiabatic character of the plastic deformation. According to the experimental results reported by Rodríguez-Martínez et al. [50] at high deformation rates, and therefore significant temperature increase, small temperature variations lead to significant differences on the volume fraction of martensite formed.

- The thermal deformation tensor rate is included in the generalized Hooke's law for hypoelastic-plastic materials, taking into account that the adiabatic increase of temperature may lead to non-negligible thermal strains. The rate of thermal deformation tensor is assumed to be isotropic

$\mathbf{d}^{\theta}=\alpha_{\theta} \dot{\theta} \mathbf{1}$

$\alpha_{\theta}$ being the coefficient of thermal expansion, $\theta$ the absolute temperature and $\mathbf{1}$ the second order unit tensor. Mahnken et al. [57] used a rule of mixtures to calculate $\alpha_{\theta}$ taking into account the different coefficients for thermal expansion of martensite and austenite. However, different authors [58] shown that the thermal expansion coefficient does not obey the law of mixtures because a state of microstresses appears between the phases when submitted to a temperature increase. Therefore the authors have chosen a constant and characteristic value of $\alpha_{\theta}$.

- The thermal softening of each solid phase is considered in the model through a thermo-viscoplastic potential, which has been defined in such a way that the yield stress follows a power thermo-viscoplastic law. These laws are commonly accepted to model strain/strain rate hardening and temperature softening [19,59-61]. The effective properties of the thermo-viscoplastic heterogeneous material are calculated using a plastic potential including viscous and thermal effects for both austenite and martensite, using the modified secant method proposed by
Suquet [62-64] and the solution algorithm developed by Papatriantafillou et al. [54].

- An original thermodynamic scheme to capture the variability of the Taylor-Quinney coefficient in austenitic steels showing strain induced martensitic transformation at high strain rates is included. Different heat sources involved in the temperature increase of the material are taken into account. These are the latent heat released due to the exothermic character of the transformation and the heat released due to austenite and martensite straining. The intrinsic dissipation in each of the constitutive phases is computed as a constant fraction of the corresponding plastic work power. The variability of the Taylor-Quinney coefficient stems from the evolution of the phase fractions and from the latent heat released upon phase transformation. Through a differential treatment of these dissipative terms, the Taylor-Quinney coefficient develops a direct connection with the martensitic transformation, and the proposed model strives to provide complementary insight regarding heat generation in dynamically phase transforming alloys, in which the heat power might be greater than the intrinsic dissipation power.

The so-called dynamic composite effect due to the progressive appearance of martensite is clearly shown in Fig. 1. The yield strength of martensite is higher than that of austenite, increasing the flow stress and strain hardening in the steel grade.

\section{Finite element modeling of dynamic tension}

Dynamic tension FE simulations are conducted in order to evaluate the effects of SIMT and plastic strain development on the energy absorption capabilities of the material. The simulations are run for strain rates ranging between $500 \mathrm{~s}^{-1} \leq \dot{\varepsilon} \leq 20,000 \mathrm{~s}^{-1}$. The authors are aware that this range of loading rates exceeds the regular experimental capabilities, however this way of proceeding is efficient to analyze the effect of the aforementioned mechanical factors on the strain localization process. Two different numerical configurations are addressed: full sample description and single element simulations.

\subsection{Full sample description}

The geometry of the tensile specimen is taken from RodríguezMartínez et al. [50], Fig. 2. The mesh consists of 10,941 eight-node

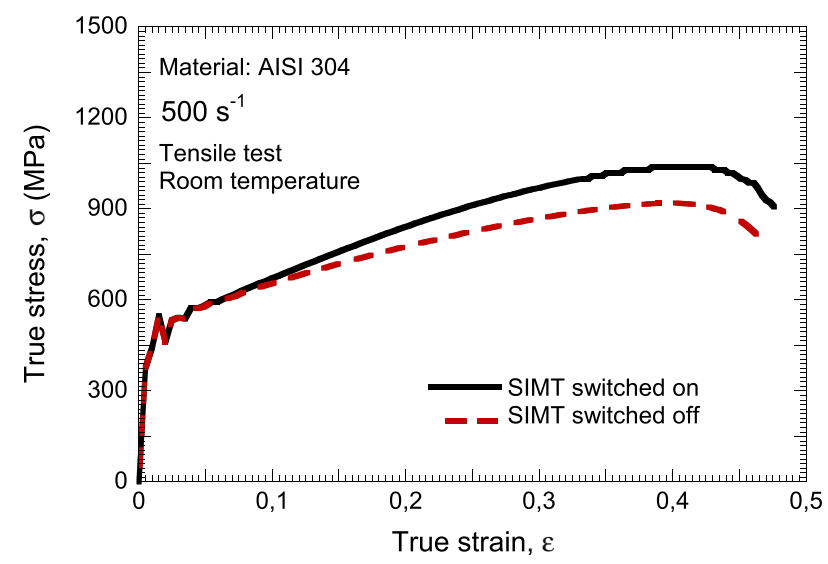

Fig. 1. Comparison between numerical predictions of the stress-strain behavior for AISI 304 grade, in which the martensitic transformation has been switched on and off $\dot{\varepsilon}=500 \mathrm{~s}^{-1}$ 


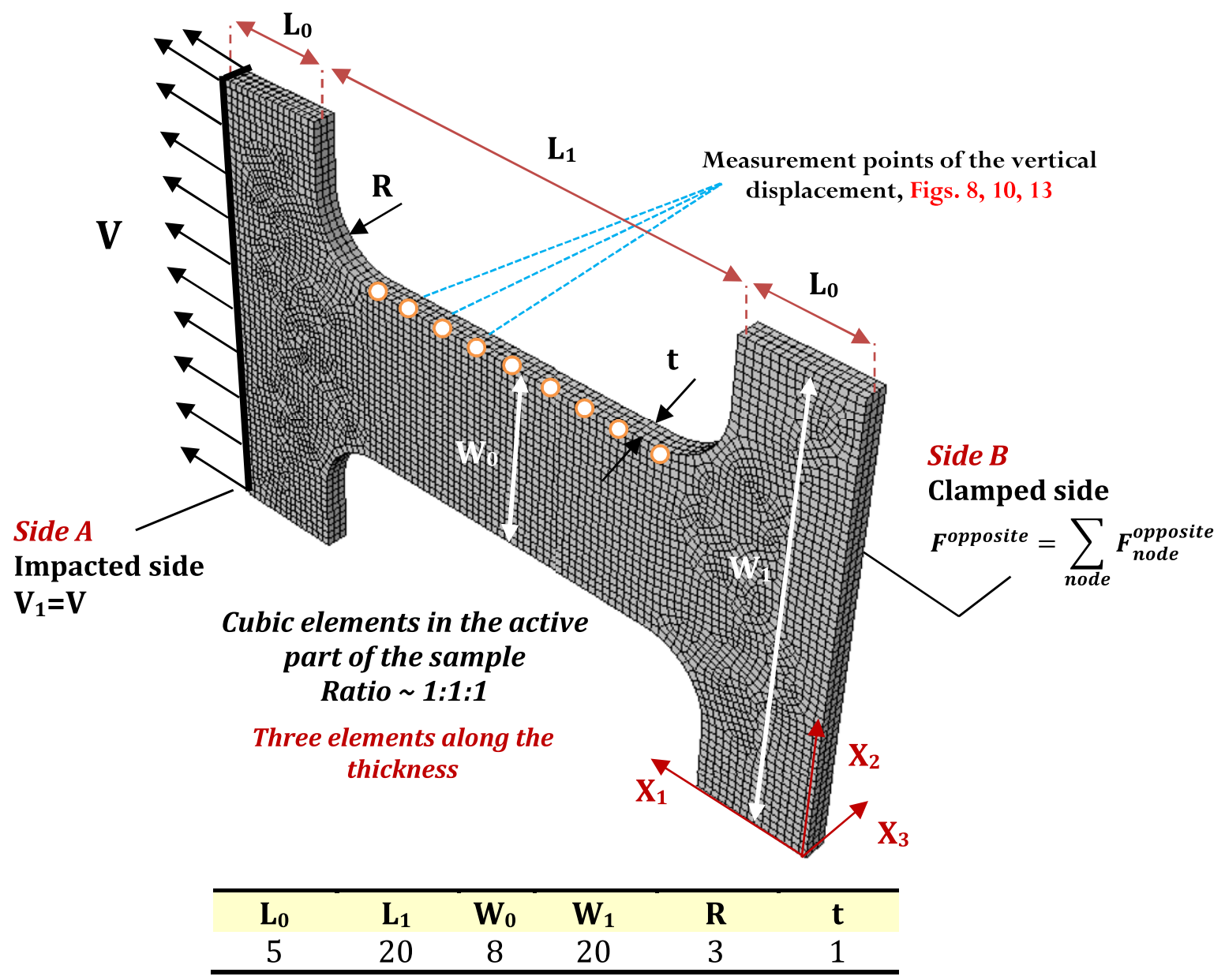

Fig. 2. Schematic representation of the $3 D$ model. Mesh, dimensions $(\mathrm{mm})$, boundary conditions and loading condition.

tri-linear brick elements with reduced integration. The integral viscoelastic approach available in ABAQUS/Explicit [65] has been used to prevent hourglass deformation modes, with the scale factor used for all hourglass stiffnesses being equal to one. According to the considerations reported by Zukas and Scheffer [66], the gauge of the specimen has been meshed using elements whose aspect ratio was close to $1: 1: 1\left(\approx 1 / 3 \times 1 / 3 \times 1 / 3 \mathrm{~mm}^{3}\right)$. Loading in the specimen has been introduced through the following boundary condition: an axial velocity $V$ instantaneously applied on side A see Fig. 2 - which remains constant throughout the entire process $[40,67]$.

Two different initial conditions have been applied:

- No-field: The initial condition is $V=0$. The application of this initial condition to a specimen initially at rest leads to the propagation of a plastic wave front along the longitudinal axis of the sample [21,68]. This configuration is representative of a typical experimental setup.

- Field: The axial velocity along the length of the sample $V_{1}$ is initialized as schematically described in Fig. 3.

This initial condition avoids the abrupt motion of the sample along the axial direction at $t=0$. Here should be noted that the initial velocity along directions $X_{2}$ and $X_{3}$ is set to 0 . The authors are aware that this leads to acceleration of the sample along $X_{2}$ and $X_{3}$ directions at the beginning of loading. Moreover, let us note that since the reference configuration is stress-free at the onset of loading the sample is subjected to an initial stress increase as a consequence of the load application. However, it is reasonable to assume that the distortion of the strain field along the longitudinal axis of the specimen is the dominant mechanism governing the process of necking formation. The potential strain disturbances along $X_{2}$ and $X_{3}$ directions and the stress increase at the beginning

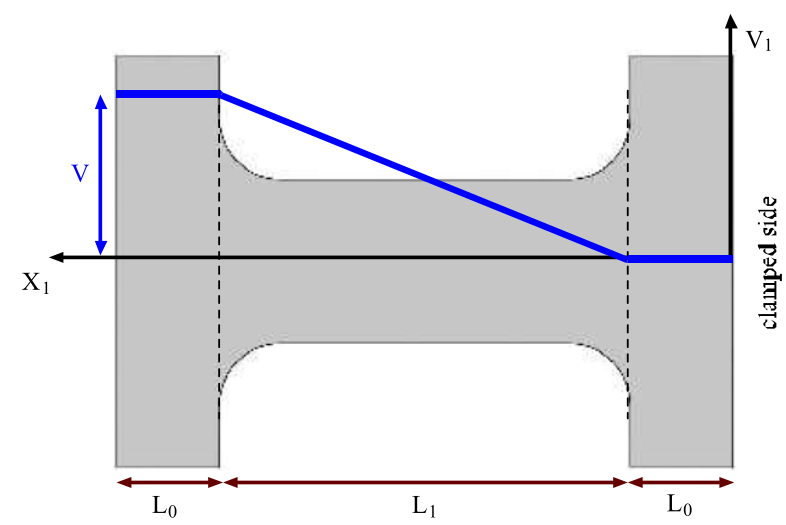

Fig. 3. Schematic representation of the initial velocity field applied to the sample in the field simulations. 
of loading may play a secondary role in the neck inception. In forthcoming sections of this paper the effectiveness of this initial condition in minimizing the propagation of the plastic wave front is strengthened.

It is worth noting that in order to mimic most of the existing experimental tests, no initial numerical or geometrical imperfection has been assumed. A regular mesh was used to minimize mesh-related imperfections, so that the necking instability would develop from an initially smooth surface. This procedure has been shown effective in reproducing the localization mechanics of the dynamic tension problem as demonstrated by Rusinek et al. [40].

\subsection{Single element configuration}

FE models with a single element having one quadrature point allow efficient integration of the constitutive models under particular loading conditions. The effect of a given specimen geometry is discarded and the results yield the specific response of the constitutive models. Stress-strain characteristics obtained from this configuration are used as a reference for evaluation of the results obtained from the full sample simulations. One $1 \times 1 \times 1 \mathrm{~mm}^{3}$ 8 -node tri-linear brick element with reduced integration was used in the simulations. Fig. 4 shows the loading and boundary conditions imposed to the element to define the tensile stress state. It should be noted that for a single element having one integration point the generation of a plastic wave front is precluded. There is no upper limit in velocity which impedes determination of the stress-strain material characteristics, i.e. the critical impact velocity is avoided in this approach.

\section{Results and analysis}

The reported stress-strain curves are obtained from the full sample numerical simulations following the regular procedure used in experimentation. The sample displacement (used to determine the strain in the sample gauge during the simulations) is recorded at the impacted side of the specimen and the force (used to determine the stress) at the clamped end - see Fig. 2. Moreover, similarly to Xue et al. [21] and Rodríguez-Martínez et al. [69], the localized necking strain $\varepsilon_{\text {neck }}$ - from this point on denoted simply by necking strain - is determined by the condition $\mathrm{d} u_{1} / \mathrm{d} t=0$, where $u_{1}$ is the longitudinal displacement in the $X_{1}$ direction measured at a node beside the necked zone, in the direction toward the clamped side, and $t$ refers to time, Fig. 5. Once the necking strain is known, it can be used as the upper limit of integration of the stress-strain curves for the determination of the energy absorbed by the sample until strain localization occurs, $E_{s}$.

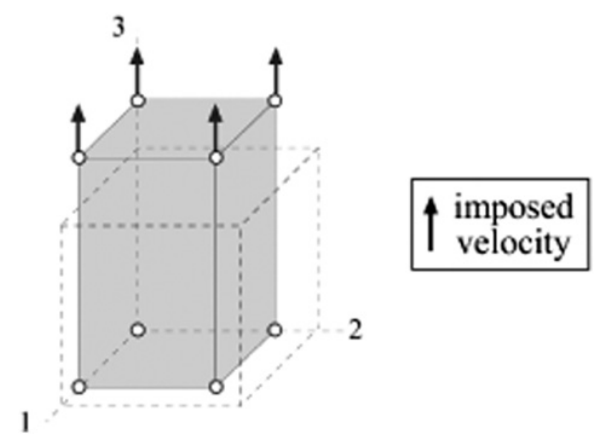

Fig. 4. Schematic representation of the single element model. Boundary and loading conditions.

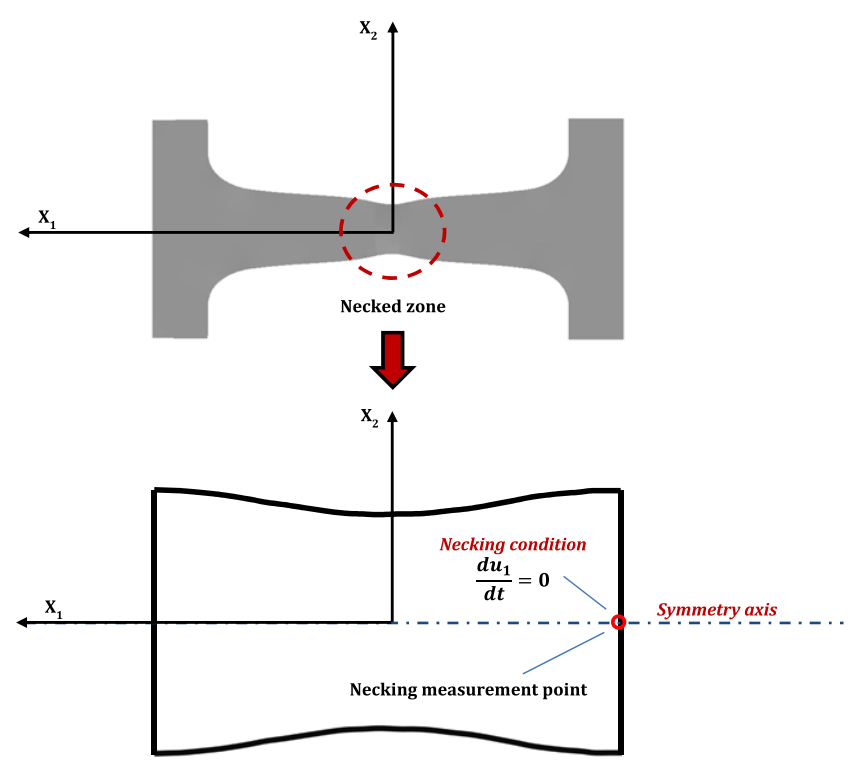

Fig. 5. Schematic representation of necked zone showing the measurement point used for determination of the localized necking condition.

\subsection{The role of SIMT in presence of plastic waves}

The role of SIMT on the energy absorption capability of the material in presence of plastic waves is evaluated using no-field initial conditions. For that task, the transformation has been systematically switched on and off. Fig. 6 shows the necking strain $\varepsilon_{\text {neck }}$ and the energy absorbed by the sample $E_{S}$ as a function of the loading rate $\dot{\varepsilon}$ for simulations in which the SIMT has been activated and deactivated. Note that $10 \%$ is the percentage-value of the data considered, which is represented by the error bars.

Consider first the general behavior of $\varepsilon_{\text {neck }}$ and $E_{S}$ as a function of the strain rate $\dot{\varepsilon}$. For this, we will just refer to simulations in which the SIMT has been switched on - solid symbols in Fig. 6. It can be observed that for strain rates up to $\sim 3000 \mathrm{~s}^{-1}$ the necking strain and the energy absorbed by the sample slightly increase with impact velocity. This comprises the range of loading rates for which necking takes place in the middle of the sample, Fig. 6 . Then, within

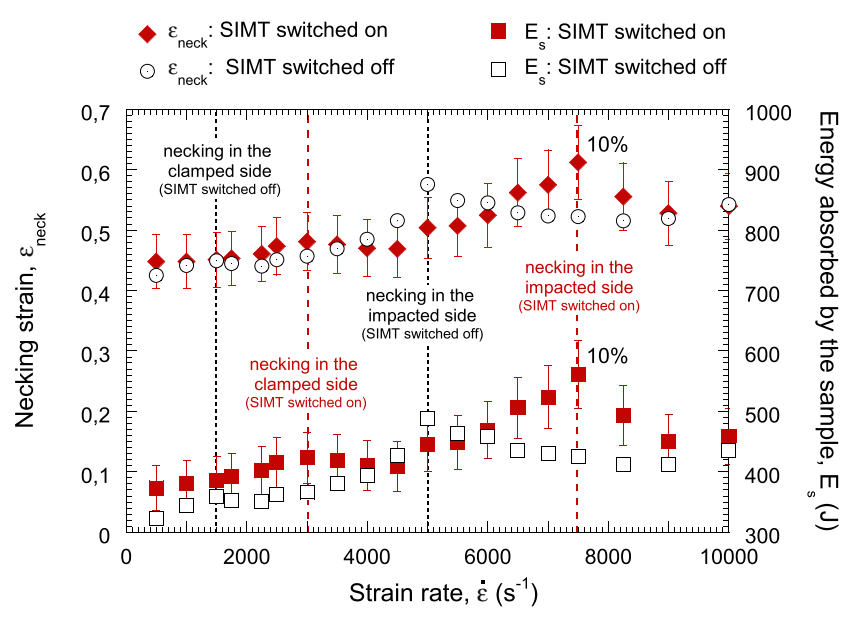

Fig. 6. Necking strain $\varepsilon_{\text {neck }}$ and energy absorbed by the sample $E_{\mathrm{s}}$ as a function of the loading rate $\dot{\varepsilon}$ for no-field simulations in which the martensitic transformation has been switched on and off. 
certain range of strain rates, up to $4500 \mathrm{~s}^{-1}$ approximately, $\varepsilon_{\text {neck }}$ and $E_{s}$ slightly decrease with impact velocity. This behavior corresponds to the loading rates for which the neck takes place closer to the clamped side, Fig. 7. When the neck is incepted close to the clamped side, the shoulder of the specimen limits the development of plastic deformation inducing large strain gradients responsible for decreasing $\varepsilon_{\text {neck. }}$ At higher strain rates, the necking location starts moving from the clamped side to the impacted end leading to a continuous rise in $\varepsilon_{\text {neck }}$ and $E_{s}$ with impact velocity which extends until attainment of the CIV at $\sim 150 \mathrm{~m} / \mathrm{s}$ (which corresponds to $7500 \mathrm{~s}^{-1}$ ), Fig. 6 . Then, the sample ductility continuously decreases with loading rate. Here it should be noted that in order to observe a drastic reduction in ductility beyond the CIV, it is necessary to analyze specimens showing larger length/width and length/thickness ratios, as pointed out by Von Kàrman and Duwez [44]. It is worth noting that identical relationships between $\varepsilon_{\text {neck}}, E_{s}$ and $\dot{\varepsilon}$ are observed in the case of deactivated SIMT; the only difference lies in the loading velocity values for which the neck takes place in the middle of the gauge, in the clamped side or in the impacted side, Fig. 7. In the case of no-SIMT, the shift of the neck (both variants, i.e. necking closer to the clamped side, necking closer to the impacted side) occurs at lower impact velocities due to lower material flow stress and strain hardening. The calculated results concerning the general dependence of necking strain and energy absorbed by the sample on impact velocity and necking location are all well documented in the literature $[40,45,67]$. This clearly supports the idea that necking location and necking strain are direct consequence of test loading rate, material constitutive behavior and plastic wave propagation (in addition to other factors related to the geometry and dimensions of the specimen, material density) and, especially at high strain rates, cannot be considered the result of a random process governed by material or geometrical defects.

Next, let us identify the contribution of the SIMT to the calculated values of $\varepsilon_{\text {neck }}$ and $E_{s}$. At low strain rates, up to $\sim 4000 \mathrm{~s}^{-1}$, the necking strain and the energy absorbed by the sample until necking are slightly larger if the SIMT is active. This behavior could be expected since the martensitic transformation increases the material strain hardening, the latter being a variable involved in necking retardation [21]. It is worth noting that the relationship between improved strain hardening and necking retardation has been frequently presented as universal in the literature. However this is not the case for boundary value problems involving plastic wave propagation. This is illustrated in Fig. 6 for the range of strain rates $4000 \mathrm{~s}^{-1}<\dot{\varepsilon}<6000 \mathrm{~s}^{-1}$. Within these loading rates both necking strain and energy absorbed by the sample are larger when the martensitic transformation is switched off. This unexpected behavior, barely reported in the literature to the authors knowledge, is caused by the plastic wave front triggered by the abrupt motion of the impacted side at $t=0$. In other words, the plastic wave propagation at the onset of loading influences the necking position, and thus the ductility of the sample as discussed in
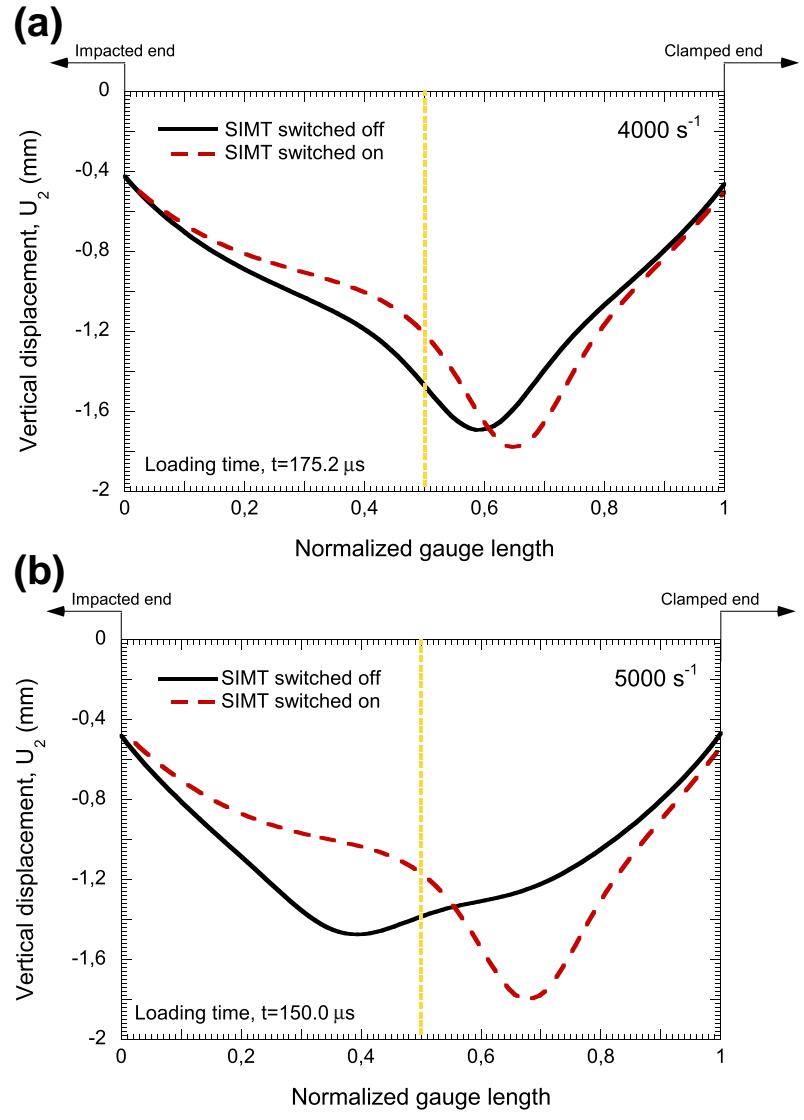

Fig. 8. Vertical displacement of the gauge length as a function of the normalized gauge length for simulations in which the SIMT has been alternatively switched on and off. (a) Strain rate $\dot{\varepsilon}=4000 \mathrm{~s}^{-1}$, loading time $t=175.2 \mu \mathrm{s}$. (b) Strain rate $\dot{\varepsilon}=5000 \mathrm{~s}^{-1}$, loading time $t=150.0 \mu \mathrm{s}$.

the previous paragraph. A clear illustration of the influence of necking position on the sample ductility is reported in Fig. 8, where the transverse displacement of the specimen in the $X_{2}$ direction is depicted as a function of the normalized gauge length. For $\dot{\varepsilon}=4000 \mathrm{~s}^{-1}$ and $\dot{\varepsilon}=5000 \mathrm{~s}^{-1}$ the neck takes place closer to the clamped end when the SIMT is switched on. Furthermore, for these loading rates, the neck is more developed in the case of activated SIMT. In other words, the maximum vertical displacement is larger in the case of activated SIMT. For $6000 \mathrm{~s}^{-1}<\dot{\varepsilon}<10,000 \mathrm{~s}^{-1}$ the neck takes place close to the impacted end independently on the martensitic transformation, leading to larger values of $\varepsilon_{\text {neck }}$ and $E_{S}$ if the SIMT is active. Finally it is worth noting that for strain rates $\dot{\varepsilon} \gtrsim 10,000 \mathrm{~s}^{-1}$ the CIV has been largely exceeded for both, SIMT switched on and SIMT

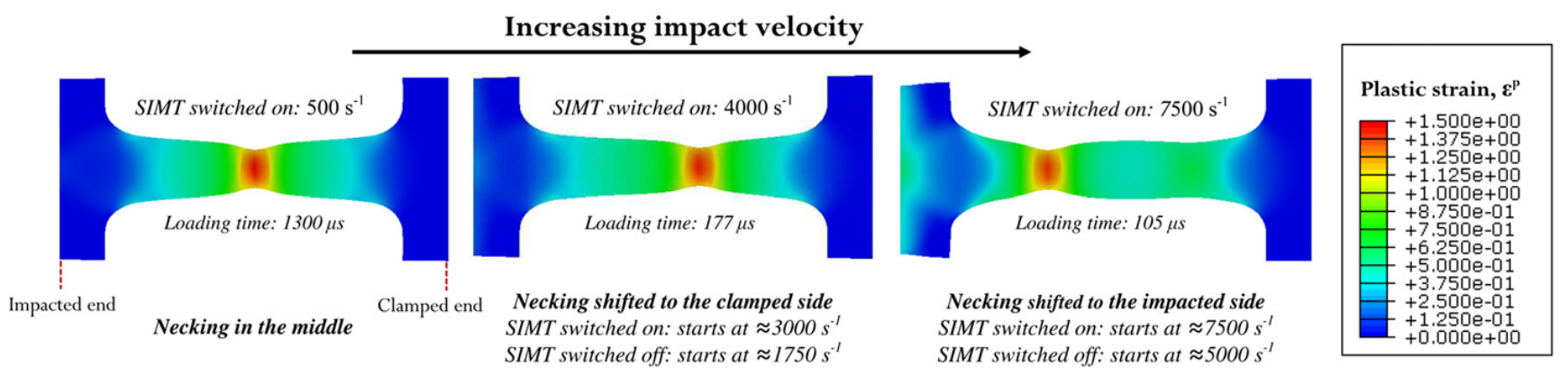

Fig. 7. Illustration of the interplay between initial strain rate $\dot{\varepsilon}$ and necking location. 


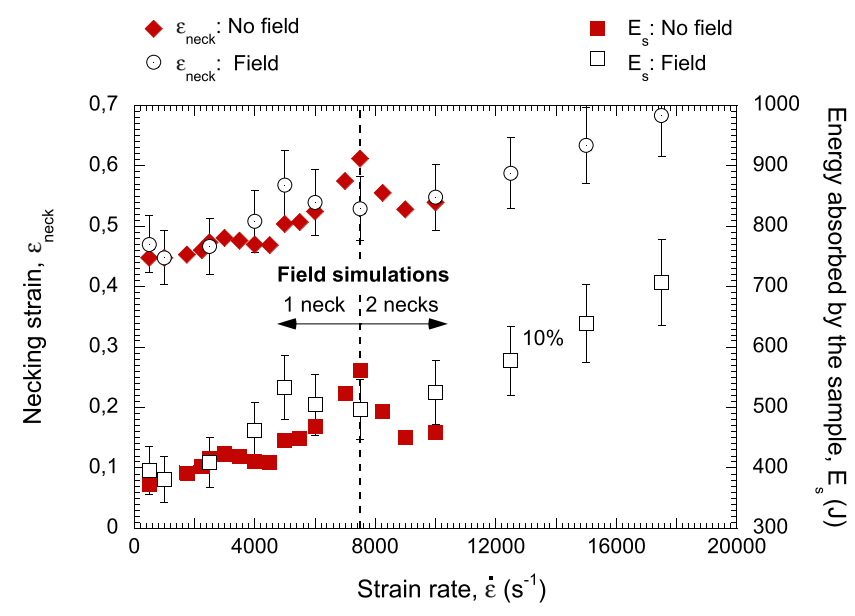

Fig. 9. Necking strain $\varepsilon_{\text {neck }}$ and energy absorbed by the sample $E_{s}$ as a function of the loading rate $\dot{\varepsilon}$ for SIMT simulations in which the initial velocity field has been switched on and off.

switched off simulations and the energy absorbed by the sample becomes independent of the material description.

\subsection{The role of plastic waves}

The role of plastic wave propagation on the onset of necking is evaluated through the comparison of field and no-field simulations in which the SIMT is active. This analysis is split into two parts.
Firstly, we analyze the different results obtained from the field and no-field simulations in full sample description simulations and their comparison with the single element computations. The second part addresses specifically the material response in the field simulations.

- Fig. 9 shows the necking strain $\varepsilon_{\text {neck }}$ and the energy absorbed by the sample $E_{S}$ as a function of the loading rate $\dot{\varepsilon}$ for field and no-field simulations. Within the range of strain rates $\dot{\varepsilon}<3000 \mathrm{~s}^{-1}$ the results obtained using both initial velocity conditions are practically identical. In both cases the neck is incepted in the middle of the sample. Within the range $3000 \mathrm{~s}^{-1}<\dot{\varepsilon}<7500 \mathrm{~s}^{-1}$ the difference arises and both $\varepsilon_{\text {neck }}$ and $E_{S}$ are significantly larger in the case of the field simulations. Then, in the case of no-field simulations the neck occurs in the clamped end and in the case of field computations the neck still occurs in the middle of the sample. Next, within the range $7500 \mathrm{~s}^{-1}<\dot{\varepsilon}<10,000 \mathrm{~s}^{-1}$ the trend is inverted and $\varepsilon_{\text {neck }}$ and $E_{s}$ are larger in the case of no-field calculations. For field simulations, a transition to two evenly spaced necks appears as strain rate increases, leading to a transient decrease in the energy required for necking formation, as will be explained later. In the case of no-field simulations, the neck is nucleated in the impacted end leading to the CIV. It can be stated that as soon the neck leaves the middle of the sample in the no-field computations, the difference between field and no-field simulations sets in. As mentioned earlier, the plastic wave front generated by the impact in the case of the no-field simulations is responsible for such behavior. Consequently, at strain rates above $9000 \mathrm{~s}^{-1}$, the necking strain for the no-field
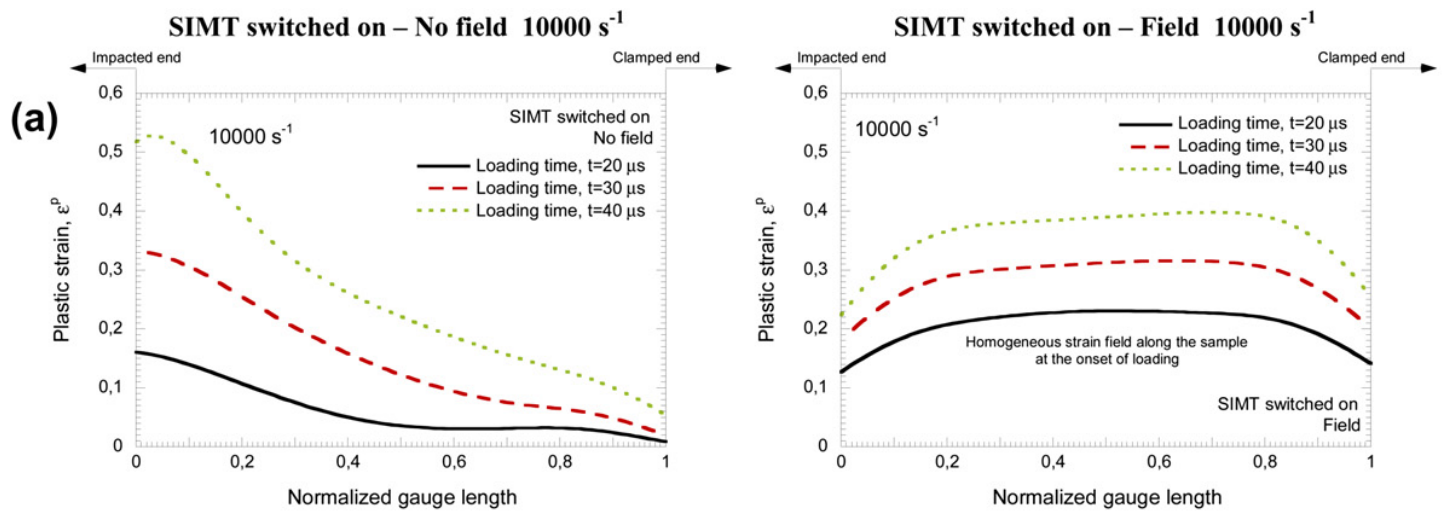

(b)
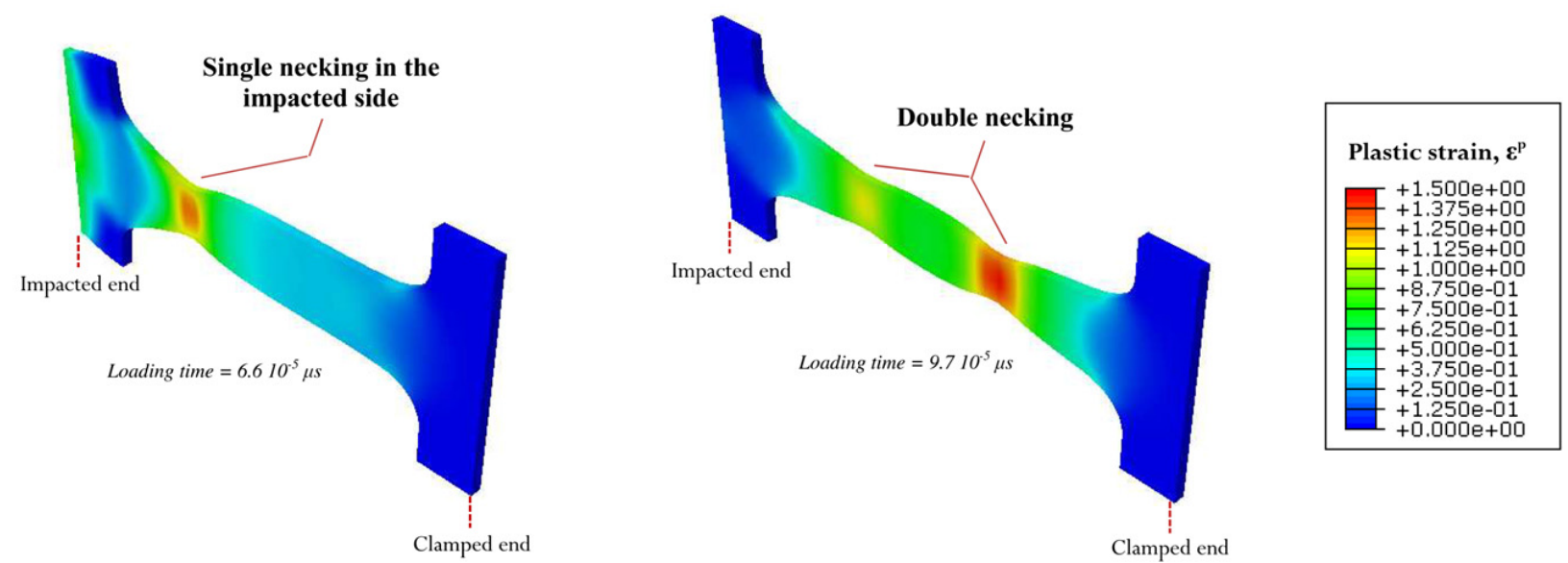

Fig. 10. (a) Plastic strain upon the normalized gauge length at $10,000 \mathrm{~s}^{-1}$ for no-field and field simulations in which the SIMT has been switched on. (b) Contours of plastic strain at $10,000 \mathrm{~s}^{-1}$ for no-field and field simulations in which the SIMT has been switched on. 
calculation keeps lower than that corresponding to the field case. Fig. 10-a shows the plastic strain along the normalized gauge length in the case of $\dot{\varepsilon}=10,000 \mathrm{~s}^{-1}$ for both initial velocity conditions and different loading times. It can be observed that if the velocity field is not initialized, the plastic strain concentrates close to the impacted side from the very beginning of loading similarly to the solution proposed by Von Kàrman and Duwez [44]. On contrary, if the velocity field is initialized, the plastic strain in the sample at the beginning of loading is largely constant. This confirms the role of the initial velocity field minimizing the plastic wave propagation. In addition, the results clearly indicate that the plastic waves, and therefore the necking location, distort the necking strain of the material. Figs. 11 and 12 show the comparison between stress-strain curves obtained from the full sample computations and the single element simulations for field and no-field conditions at two different initial strain rates, $\dot{\varepsilon}=4000 \mathrm{~s}^{-1}$ and $\dot{\varepsilon}=7500 \mathrm{~s}^{-1}$. It can be observed that the stress-strain characteristics obtained from the no-field simulations and the single element results do not match, especially at low strain levels. This difference increases with the impact velocity. In other words, as soon as the neck does not take place in the middle of the gauge the measured material characteristic in the no-field simulations is not representative of the real material behavior. This finding demonstrates that the velocity which imposes an upper limit to the dynamic tension test for determining material the actual stress-strain curve of the material is not the CIV but the velocity which causes the necking to move from

(a)
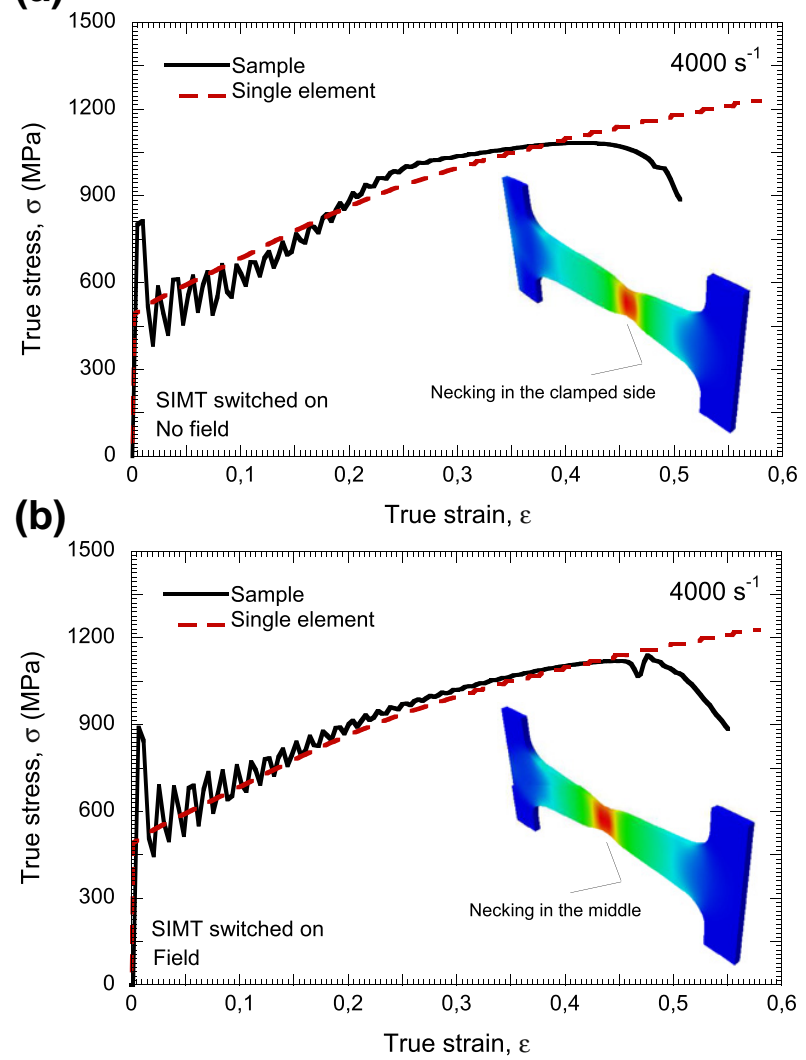

Fig. 11. Comparison between stress-strain curves for simulations using the full sample description and the single element. SIMT is switched on. Loading rate $4000 \mathrm{~s}^{-1}$. (a) Nofield simulation, (b) field simulation.

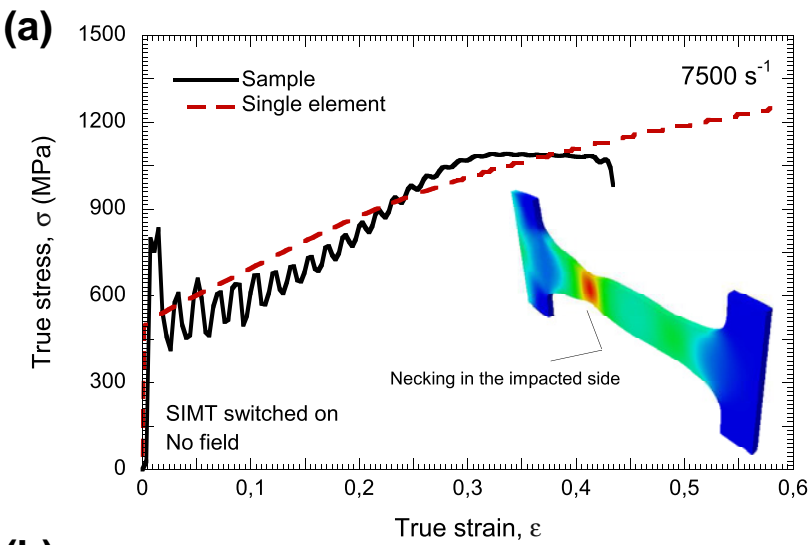

(b)

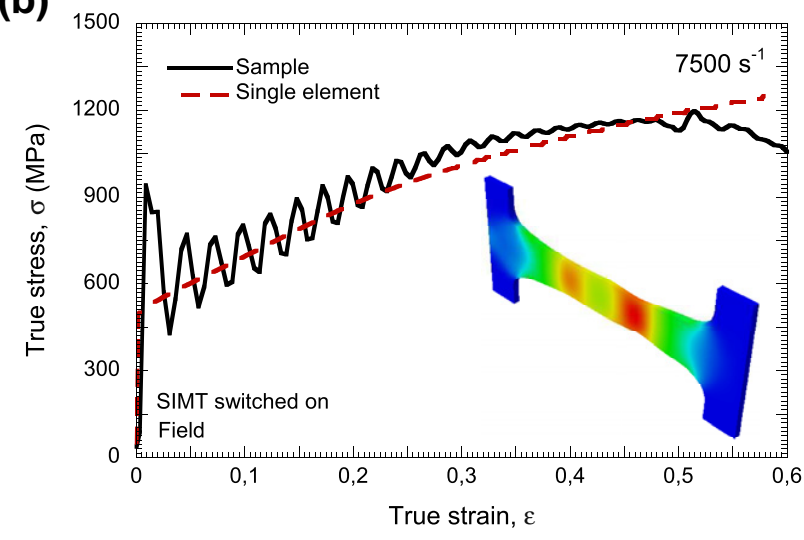

Fig. 12. Comparison between stress-strain curves for simulations using the full sample description and the single element. SIMT is switched on. Loading rate $7500 \mathrm{~s}^{-1}$. (a) No-field simulation, (b) field simulation.

the center of the sample to the clamped end. Beyond this limit, the displacement recorded at the impacted side and the force recorded at the clamped side do not correspond to a uniform state of stress and strain along the specimen, as needed for a proper interpretation of the experimental measurements. This observation is relevant for experimental work, and the results shown here were not previously reported to the best of the authors knowledge.

- Consider now the specimen response in the field simulations. From a general point of view, the results shown in Fig. 9 reveal that in the absence of plastic wave propagation, both $\varepsilon_{\text {neck }}$ and $E_{s}$ increase with loading rate - this is not true within $4500 \mathrm{~s}^{-1}<\dot{\varepsilon}<7500 \mathrm{~s}^{-1}$ as discussed later. This behavior seems to be explained by the role played by strain rate $\dot{\varepsilon}$ on necking retardation $[19,23,29]$. As expected, the CIV is avoided in absence of plastic waves. Moreover, it is worth nothing that for the lower strain rates considered, up to $\sim 7500 \mathrm{~s}^{-1}$, a single neck located in the middle of the gauge is formed. Then, this single neck suddenly gives way to the nucleation of two (rather) evenly spaced necks along the gauge of the sample, Fig. 10, that are also found at higher strain rates. Following Rodríguez-Martínez et al. [69] this transition may be related to material inertia aspects; taking into account that the term inertia not only covers material density but it also accounts for the intrinsic effects that sample dimensions, flow stress level and loading rate all have on necking inception as described elsewhere $[19,23,29]$. This may explain the nucleation of two regularly spaced necks assuming that at $\sim 7500 \mathrm{~s}^{-1}$, the elongation of the sample before necking is such that it permits the 


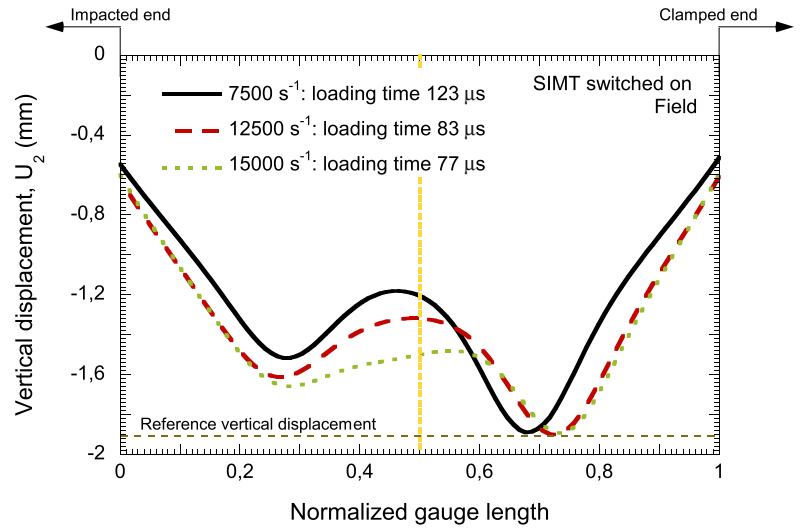

Fig. 13. Vertical displacement of the gauge length as a function of the normalized gauge length for field simulations in which the SIMT has been switched on. Three different loading rates are illustrated: $7500 \mathrm{~s}^{-1}, 12,500 \mathrm{~s}^{-1}$ and $15,000 \mathrm{~s}^{-1}$. The loading time has been set in order to obtain the same maximum vertical displacement for the three cases considered.

promotion of a more favorable wavelength mode for the necking formation. This more favorable wavelength should to be at least twice shorter than the stretched gauge allowing the formation of two necks. The transition to a more favorable wavelength is accompanied by a decrease in the energy required for necking formation which may explain the transient decrease in the necking strain reported in Fig. 9 within the range $4500 \mathrm{~s}^{-1}<\dot{\varepsilon}<7500 \mathrm{~s}^{-1}$. Moreover, it was previously noted that when the necks are incepted close to the shoulders of the sample, the development of the plastic deformation gets limited, which can act as an additional factor that decreases the necking strain within this range of loading rates. It should be highlighted that while the transition from the formation of a single neck to the formation of two necks in the field simulations is dictated by material inertia aspects, the necking location in the no-field simulations was dictated by the plastic wave propagation. Fig. 13 illustrates the vertical displacement of the gauge length as a function of the normalized gauge length for different field simulations. Three selected strain rates are $7500 \mathrm{~s}^{-1}, 12,500 \mathrm{~s}^{-1}$ and $15,000 \mathrm{~s}^{-1}$, for which two necks were nucleated. The loading time has been set in order to obtain the same maximum vertical displacement for the three cases considered as indicated in Fig. 13. For the lower loading rate considered, the incepted necks develop in a rather different manner, Fig. 13. It has been detected that one of them - the one closer to the clamped side - develops first in time may be because of the disturbances resulting from the sudden rise in stress experienced by the sample at the onset of loading - see Section 4.a. Once the first neck is formed an unloading wave emanates from the necked region slowing down the growth rate of the secondary neck [70]. This explanation finds agreement with the original Mott's theory [71] and the subsequent developments by Grady and co-workers [72-74]. Moreover it can be observed that the two necks thus formed, become increasingly symmetrical as the loading rate increases, i e. as the role played by inertia increases. This behavior agrees with theoretical and numerical observations reported elsewhere for other multiple necking problems [22,27,69].

\subsection{The role of SIMT in absence of plastic waves}

The role of SIMT in absence of plastic waves on the energy absorption capability of the material is evaluated using field initial

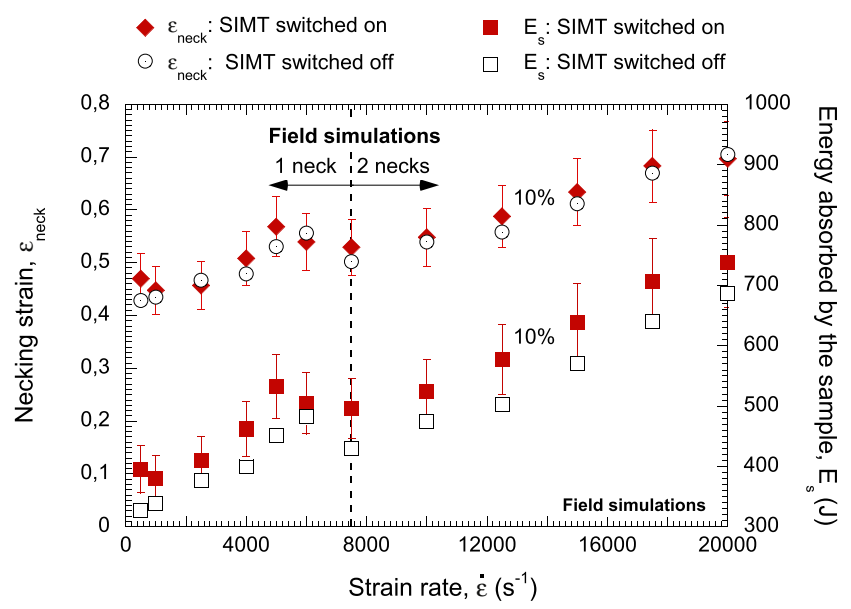

Fig. 14. Necking strain $\varepsilon_{\text {neck }}$ and energy absorbed by the sample $E_{s}$ as a function of the loading rate $\dot{\varepsilon}$ for field simulations in which the martensitic transformation has been switched on and off alternatively.

conditions. Fig. 14 shows the necking strain $\varepsilon_{\text {neck }}$ and the energy absorbed by the sample $E_{S}$ as a function of the loading rate $\dot{\varepsilon}$ for simulations in which the SIMT has been activated and deactivated. It can be observed that now the picture is completely different to that reported in Fig. 6; the relative influence of the SIMT on the material response is found to be highly dependent on the presence or absence of the plastic waves.

It is worth noting that the recorded values of $\varepsilon_{\text {neck }}$ seem to be rather independent of the martensitic transformation, in fact in some cases $\varepsilon_{\text {neck }}$ is larger in the case of deactivating the SIMT. The explanation may be related to the emerging role played by inertia the concept of inertia was mentioned in Section 4.a - at high strain rates $[19,29,69]$. In other words, the stabilizing effect of the enhanced strain hardening provided by the SIMT seems to be balanced by the destabilizing effect of its associated increase in flow stress [23]. However, although the necking strain values are quite similar for both conditions, the computations in which the SIMT is switched on show larger values of $E_{s}$; it has to be noted that such difference tends to decrease with the increasing loading rate. In other words, the SIMT does not provide enhanced ductility to the material but it is still beneficial in terms of energy absorption due to the larger material flow stress. This calls for a re-assessment of the usefulness of the SIMT for enhancing material ductility in high strain rate applications, for which the material response may be governed by inertia effects.

\section{Conclusions}

In this paper the processes of strain localization and necking formation in AISI 304 steel sheets subjected to dynamic tension have been investigated using finite element simulations. Two different numerical configurations are addressed: single element simulations and full specimen geometry simulations. In the full specimen geometry calculations two different initial conditions have been applied; no-field which is representative of a regular experimental arrangement and field which allows minimizing the propagation of plastic waves along the longitudinal direction of the sample. The material behavior is described by a constitutive model proposed by the authors which includes explicitly the SIMT, thus characterizing the response of the AISI 304 at high loading rates.

The analysis is focused on the effects of SIMT and plastic wave propagation on the process of flow localization, which in turn 
determines the energy absorption capacity of the material at high loading rates.

The main conclusions that emerge from this work are as follows:

- In presence of plastic waves, and under certain strain rate conditions, the increased strain hardening provided by the SIMT process may not delay the onset of necking, thus limiting the energy absorption capacity of the material. This unexpected behavior is barely reported in the literature, and it is related to the motion of the necking location along the gauge length.

- Once a certain impact velocity is exceeded, the presence of plastic waves in the dynamic tensile test hinders the actual material behavior. In other words, as soon as the neck does not take place in the middle of the gauge, the stress-strain curve obtained from dynamic tensile tests is not representative of the actual material behavior. This finding demonstrates that the velocity which imposes an upper limit to the dynamic tension test for determining material properties is not the CIV, but the velocity which causes the necking to move from the center of the sample.

- In the absence of plastic waves, and under certain strain rate conditions, the SIMT may not provide the anticipated enhanced material ductility. The stabilizing effect of the enhanced strain hardening provided by the SIMT is balanced by the destabilizing effect of its associated increase in flow stress. This behavior seems to be a limiting factor to the homogeneous deformation behavior of the material at high strain rates. This observation calls for a re-assessment of the beneficial effects of SIMT at high loading rates, for which the material response may be governed by inertial effects.

\section{Acknowledgments}

J. A. Rodríguez-Martínez and R. Zaera express sincere gratitude to Dr. Guadalupe Vadillo, Professor José Fernández-Sáez and Professor Alain Molinari for helpful discussions on the role played by material aspects on the formation of plastic instabilities in ductile materials subjected to high strain rates.

D. Rittel acknowledges the support of Carlos III University with a Cátedra de Excelencia funded by Banco Santander during academic year 2011-2012.

The researchers of the University Carlos III of Madrid are indebted to the Comunidad Autónoma de Madrid (Project CCG10UC3M/DPI-5596) and to the Ministerio de Ciencia e Innovación de España (Project DPI/2008-06408) for the financial support received which allowed conducting part of this work.

\section{References}

[1] Karagiozova D, Mines R. Impact of aircraft rubber tyre fragments on aluminium alloy plates: II-numerical simulation using LS-DYNA. International Journal of Impact Engineering 2007;34:647-67.

[2] Varas D,Zaera R, López-Puente J Numerical modelling of the hydrodynamic ram phenomenon. International Journal of Impact Engineering 2009;36:363-74.

[3] Rusinek A, Zaera R, Forquin P, Klepaczko JR. Effect of plastic deformation and boundary conditions combined with elastic wave propagation on the collapse site of a crash box. Thin-Walled Structures 2008;46:1143-63.

[4] Kazanci Z, Bathe K. Crushing and crashing of tubes with implicit time integration. International Journal of Impact Engineering 2012;42:80-8.

5] Wang L, Yang L, Huang D, Zhang Z, Chen G. An impact dynamics analysis on a new crashworthy device against ship-bridge collision. International Journal of Impact Engineering 2008;35:895-904.

[6] Ehlers S. The influence of the material relation on the accuracy of collision simulations. Marine Structures 2010;23:462-74.

[7] Miguelez MH, Zaera R, Molinari A, Cheriguene R, Rusinek A. Residual stresses in orthogonal cutting of metals: the effect of thermomechanical coupling parameters and of friction. Journal of Thermal Stresses 2009;32:269-89.

[8] Verleysen P, Peirs J, Slycken JV, Faes K, Duchene L. Effect of strain rate on the forming behaviour of sheet metals. Journal of Materials Processing Technology $2011 ; 211: 1457-64$.
[9] Considère AG. L'emploi du fer de l'acier dans les constructions. Ann Ponts et Chausses 1885;9:574-5.

[10] Hill R. A general theory of uniqueness and stability in elastic-plastic solids. Journal of the Mechanics and Physics of Solids 1958;6:236-49.

[11] Miles J. Bifurcation in plastic flow under uniaxial tension. Journal of the Mechanics and Physics of Solids 1971;19:89-102.

[12] Hutchinson J, Miles J. Bifurcation analysis of the onset of necking in an elastic/ plastic cylinder under uniaxial tension. Journal of the Mechanics and Physics of Solids 1974;22:61-71.

[13] Woodford D. Strain rate sensitivity as a measure of ductility. Transactions of the American Society for Metals 1969;62:291-3.

[14] Ghosh AK. The influence of strain hardening and strain-rate sensitivity on sheet metal forming. Transactions ASME Journal of Engineering Materials Technology 1977;99:264-74.

[15] Hart EW. A theory for flow of polycrystals. Acta Metallurgica 1967;15:1545-9.

[16] Ghosh AK. Tensile instability and necking in materials with strain hardening and strain-rate hardening. Acta Metallurgica 1977;25:1413-24.

[17] Klepaczko JR. Generalized conditions for instability in tension. International Journal of Mechanical Sciences 1968;10:297-313.

[18] Hutchinson JW, Neale KW. Influence of strain rate sensitivity on necking under uniaxial tension. Acta Metallurgica 1977;25:839-46.

[19] Mercier S, Molinari A. Analysis of multiple necking in rings under rapid radial expansion. International Journal of Impact Engineering 2004;30:403-19.

[20] Zhou F, Molinari JF, Ramesh KT. An elasto-visco-plastic analysis of ductile expanding ring. International Journal of Impact Engineering 2006;33:880-91.

[21] Xue Z, Vaziri A, Hutchinson JW. Material aspects of dynamic neck retardation. Journal of the Mechanics and Physics of Solids 2008;56:93-113.

[22] Mercier S, Granier N, Molinari A, Llorca F, Buy F. Multiple necking during the dynamic expansion of hemispherical metallic shells, from experiments to modelling. Journal of the Mechanics and Physics of Solids 2010;58:955-82.

[23] Vadillo G, Rodríguez-Martínez JA, Fernández-Sáez J. On the interplay between strain rate and strain rate sensitivity on flow localization in the dynamic expansion of ductile rings. International Journal of Solids and Structures 2012; 49:481-91.

[24] Fressengeas C, Molinari A. Inertia and thermal effects on the localization of plastic flow. Acta Metallurgica 1985;33:387-96.

[25] Shenoy VB, Freund LB. Necking bifurcations during high strain rate extension. Journal of the Mechanics and Physics of Solids 1999;47:2209-33.

[26] Pandolfi A, Krysl P, Ortiz M. Finite element simulation of ring expansion and fragmentation: the capturing of length and time scales through cohesive models of fracture. International Journal of Fracture 1999;95:297.

[27] Sørensen NJ, Freund LB. Unstable neck formation in a ductile ring subjected to impulsive radial loading. International Journal of Solids and Structures 2000; 37:2265-83.

[28] Becker R. Ring fragmentation predictions using the Gurson model with material stability conditions as failure criterion. International Journal of Solids and Structures 2002;39:3555-80.

[29] Mercier S, Molinari A. Predictions of bifurcations and instabilities during dynamic extensions. International Journal of Solids and Structures 2003;40: 1995-2016.

[30] Rusinek A, Zaera R. Finite element simulation of steel ring fragmentation under radial expansion. International Journal of Impact Engineering 2007;34: 799-822.

[31] Rusinek A, Klepaczko JR. Experiments on heat generated during plastic deformation and stored energy for TRIP steels. Materials and Design 2009;30:35-48.

[32] Rodríguez-Martínez JA, Pesci R, Rusinek A, Arias A, Zaera R, Pedroche DA Thermo-mechanical behaviour of TRIP 1000 steel sheets subjected to low velocity perforation by conical projectiles at different temperatures. International Journal of Solids and Structures 2010;47:1268-84.

[33] Rodríguez-Martínez JA, Rusinek A, Pesci R. Experimental survey on the behaviour of AISI 304 steel sheets subjected to perforation. Thin-Walled Structures 2010;48:966-78.

[34] Zaera R, Rodríguez-Martínez JA, Casado A, Fernández-Sáez J, Rusinek A, Pesci R. A constitutive model for analyzing martensite formation in austenitic steels deforming at high strain rates. International Journal of Plasticity 2012; 29:77-101.

[35] Gray III GT. Classic split-Hopkinson pressure bar testing. In: Kuhn H, Medlin D, editors. ASM handbook. Mechanical testing and evaluation, Vol. 8. Materials Park, OH: ASM International; 2000. p. 462-76.

[36] Field J, Walley S, Proud W, Goldrein H, Siviour C. Review of experimental techniques for high rate deformation and shock studies. International Journal of Impact Engineering 2004;30:725-75.

[37] Staab GH, Gilat A. A direct-tension split Hopkinson bar for high strain-rate testing. Experimental Mechanics 1991;31:232-5.

[38] Tanimura S, Mimura K. Newly developed dynamic testing methods and dynamic strength of some structural materials. vol. 1 of Impact Eng. Appl. London: Proceeding of the 4th International Symposium on Impact Engineering; 2001. p. 57-64.

[39] Huh H, Kang WJ, Han SS. A tension split Hopkinson bar for investigating the dynamic behavior of sheet metals. Experimental Mechanics 2002:42:8-17.

[40] Rusinek A, Zaera R, Klepaczko JR, Cheriguene R. Analysis of inertia and scale effects on dynamic neck formation during tension of sheet steel. Acta Materialia 2005;53:5387-400.

[41] Hopkinson J. On the rupture of iron wire by a blow. Proceedings of the Manchester Literary and Philosophical Society 1872;11:40-5. 
[42] Hopkinson J. Further experiments on the rupture of an iron wire. Proceedings of the Manchester Literary and Philosophical Society 1872;11:119-21.

[43] Hopkinson B. The effects of momentary stresses in metals. Proceedings of the Royal Society of London 1905;74:498-506.

[44] Von Kàrman T, Duwez P. The propagation of plastic deformation in solids. Journal of Applied Physics 1950;21:987-94.

[45] Clark DS, Wood DS. The influence of specimen dimension and shape on the results in tension impact testing. The American Society of Mechanical Engineers 1950:577-85.

[46] Klepaczko JR. Review on critical impact velocities in tension and shear. International Journal of Impact Engineering 2005;32:188-209.

[47] Niordson FL. A unit for testing materials at high strain rates. Experimental Mechanics 1965;5:29-32.

[48] Hu X, Daehn GS. Effect of velocity on flow localization in tension. Acta Materialia 1996;44:1021-33.

[49] Zhang H, Ravi-Chandar K. On the dynamics of necking and fragmentation - I. real-time and post-mortem observations in $\mathrm{Al} \mathrm{6061-O.} \mathrm{International} \mathrm{Journal}$ of Fracture 2006;142:183-217.

[50] Rodríguez-Martínez JA, Pesci R, Rusinek A. Experimental study on the martensitic transformation in AISI 304 steel sheets subjected to tension under wide ranges of strain rate at room temperature. Materials Science and Engineering: A 2011;528:5974-82.

[51] Zaera R, Rodríguez-Martínez JA, Rittel D. On the Taylor-Quinney coefficient in dynamically phase transforming materials. Application to 304 stainless steel. International Journal of Plasticity 2013;40:185-201.

[52] Olson GB, Cohen M. Kinetics of strain-induced martensitic nucleation. Metallurgical Transactions A 1975;6A:791-5.

[53] Stringfellow RG, Parks DM, Olson GB. A constitutive model for transformation plasticity accompanying strain-induced martensitic transformations in metastable austenitic steels. Acta Metallurgica and Materialia 1992;40(7): 1703-16.

[54] Papatriantafillou I, Aravas N, Haidemenopoulos G. Finite element modelling of TRIP steels. Steel Research International 2004;75:732-8.

[55] Tomita Y, Iwamoto T. Constitutive modelling of trip steel and its application to the improvement of mechanical properties. International Journal of Mechanical Sciences 1995;37:1295-305

[56] Iwamoto T, Tsuta T. Computational simulation on deformation behavior of CT specimens of TRIP steel under mode I loading for evaluation of fracture toughness. International Journal of Plasticity 2002;11:1583-606.

[57] Mahnken R, Schneidt A, Antretter T. Macro modelling and homogenization for transformation induced plasticity of a low-alloy steel. International Journal of Plasticity 2009;25:183-204.

[58] Sideridis E, Kytopoulos VN, Kyriazi E, Bourkas G. Determination of thermal expansion coefficient of particulate composites by the use of a triphase model. Composites Science and Technology 2005;65:909-19.
[59] Klepaczko JR. A practical stress-strain-strain rate-temperature constitutive relation of the power form. Journal of Mechanical Working Technology 1987 15:143-65.

[60] Molinari A, Musquar C, Sutter G. Adiabatic shear banding in high speed machining of $\mathrm{Ti}-6 \mathrm{Al}-4 \mathrm{~V}$ : experiments and modeling. International Journal of Plasticity 2002;18:443-59.

[61] Khan AS, Kazmi R, Farrokh B, Zupan M. Effect of oxygen content and microstructure on the thermo-mechanical response of three $\mathrm{Ti}-6 \mathrm{Al}-4 \mathrm{~V}$ alloys: experiments and modeling over a wide range of strain-rates and temperatures. International Journal of Plasticity 2007;23:1105-25.

[62] Suquet P. Overall properties of nonlinear composites: a modified secant moduli theory and its link to Ponte Castañeda's nonlinear variational procedure. C R Acad Sci Paris, Sèrie II b 1995;320:563-71.

[63] Suquet P. Overall properties of nonlinear composites: secant moduli theories and variational bounds. In: Markov KZ, editor. Continuum models and discrete systems, proceedings of 8th international symposium. World Scientific Publishing Company; 1995. p. 290-9.

[64] Suquet P. Overall properties of nonlinear composites: remarks on secant and incremental formulations. In: Pineau A, Zaoui A, editors. Micromechanics of plasticity and damage of multiphase materials (IUTAM symposium). Kluwer; 1996. p. $149-56$.

[65] ABAQUS/Explicit. Abaqus Explicit v6.10 user's manual. Richmond, USA: ABAQUS Inc.; 2010. version 6.10 ed.

[66] Zukas JA, Scheffer DR. Practical aspects of numerical simulations of dynamic events: effects of meshing. International Journal of Impact Engineering 2000; 24:925-45.

[67] Rodríguez-Martínez JA, Rusinek A, Arias A. Relation between strain hardening of steel and critical impact velocity. Journal of Theoretical and Applied Mechanics 2009;47:645-65.

[68] Needleman A. The effect of material inertia on neck development. In: Yang WH, editor. Topics in plasticity. Ann Arbor, MI: AM Press; 1991. p. 151-60.

[69] Rodríguez-Martínez JA, Vadillo G, Fernández-Sáez J, Molinari A. Identification of the critical wavelength responsible for the fragmentation of ductile rings expanding at very high strain rates, submitted for publication.

[70] Besnard G, Hild F, Lagrange JM, Martinuzzi P, Roux S. Analysis of necking in high speed experiments by stereocorrelation. International Journal of Impact Engineering 2012;49:179-91.

[71] Mott NF. Fragmentation of shell cases. Proceedings of the Royal Society of London, Series A 1947:300-8.

[72] Grady D. Fragmentation of solids under impulsive stress loading. Journal of Geophysical Research 1981;86:1047-54

[73] Kipp M, Grady D. Dynamic fracture growth and interaction in one dimension. Journal of the Mechanics and Physics of Solids 1985;33:399-415.

[74] Grady DE, Olsen ML. A statistics and energy based theory of dynamic fragmentation. International Journal of Impact Engineering 2003;29:293-306. 